\title{
The Growth and Composition of the U.S. Labor Force
}

\author{
Vernon M. Briggs, Jr.
}

\begin{abstract}
In sharp contrast with the experiences of all other industrialized nations, the size of the labor force of the United States is growing rapidly while, simultaneously, its age, gender, and ethnic composition are changing markedly. Consequently, human resource issues present an unprecedented challenge in the nation's quest to achieve a fully employed and equitable society. New public policies that focus on labor market adjustment policies will be required if these developments are to be a boon rather than a bane to the emerging postindustrial economy.
\end{abstract}

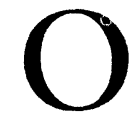

F ALL THE EXPLANATIONS FOR ECONOMIC PROGRESS BY industrialized nations during the last half of the 20th century, the most insightful has been the recognition of "human resources as the wealth of nations" $(1)$. Countries with limited physical resources, such as Japan and West Germany, have sustained superior economic performances in this new competitive era largely because they have been forced, by lack of alternatives, to focus national economic policy on human resource issues.

One approach to the study of human resources is the quantitative perspective. It examines the effects that population trends and characteristics have on the size and composition of the civilian labor force that is available for employment. Another is the qualitative vantage point. It involves issues pertaining to the actual preparation of the available labor supply for employment. In the contemporary era of rapid technological change and enhanced international competition, all industrialized nations must address qualitative issues. But no other nation in the 1980s is simultaneously confronted with a labor force that is growing as fast and whose composition is changing as rapidly as is that of the United States. Constancy of size and homogeneity of composition are convenient labor force assumptions of standard economic theory. Neither proposition, how ever, is an operational concept for understanding the current challenges to labor market adjustment and public policy formulation in the United States.

The author is a professor at the New York State School of Industrial and Labo Relations at Connell University, Ithaca, NY 14851

\section{The Relation of Population to Labor Force Changes}

A nation acquires its population in two ways: people are native born within its boundaries or foreign-born people immigrate for permanent or temporary settlement. Alterations in the size and characteristics of the population, in turn, are transmitted to the economy through labor force participation.

Analysis of the size of the native-born population that may be available for employment over time is a relatively straightforward process. The available statistics pertaining to their potential number and their characteristics are reasonably predictable. Accounting for the foreign-born portion of the population, however, has proved to be a more difficult task. Official figures on the foreign born are only available every 10 years as a product of the decennial census, but immigration to the United States is a continuous daily process.

Immigration accounted for at least one-third of the annual growth rate of the U.S. population (and probably a higher percentage of the labor force) in the 1980s. It is anticipated that the percentage will increase in the 1990s. Despite the complex and highly legalistic nature of the nation's immigration and refugee admission systems, substantial illegal immigration has circumvented these formal procedures. Measuring the size and flow of illegal immigrants has been a frustrating process (2). Obviously, there are no official data series. Only administrative data on actual apprehensions by the U.S. Immigration and Naturalization Service are available. These numbers have soared to record heights in the mid1980s-totaling more than 1.2 million apprehensions in 1986. But apprehension statistics include multiple countings of the same people so they cannot be used to measure the actual number of individuals involved. On the other hand, it is commonly acknowledged that the vast majority of illegal immigrants are never apprehended-especially those who overstay their visas and who mostly come from nations other than Mexico. Yet even most Mexicans, who usually cross the border without a visa and who are believed to account for about one-half of the annual flow of illegal immigrants, eventually get into the United States through sheer repetition of entry efforts.

Immigration flows are also less predictable because immigration policy in the United States is set on purely political criteria. The economic implications of various administrative decisions, judicial 
rulings, and legislative changes that shape the size and composition of immigration flows are seldom the subject of careful research. Thus, the employment consequences of immigration and refugee policies cannot be adequately anticipated. The recently enacted Immigration Reform and Control Act of 1986, for instance, contains four different amnesty programs that will allow millions of illegal immigrants and others whose admission legality was previously in question to adjust their status to become permanent resident aliens. If they choose, all may eventually become naturalized citizens. In some cases, the amnesty beneficiaries will be able to have their immediate relatives (spouses, children, and parents) join them at once. All will be able to reunify their families eventually. The new law also greatly liberalized the provisions that allow foreign temporary workers to be employed in the future in the United States. Hence, no one knows what the ultimate population and employment effects of this historic legislation will be other than to say that millions of people will be involved over the next 10 years.

With regard to both the native-born and the foreign-born population, there is, of course, some annual emigration. Since 1958, however, the federal government has ceased collecting such data. Experience has demonstrated that most emigrants are reluctant to officially give up their U.S. citizenship or permanent resident alien status. These emigrants fear that they may change their minds and eventually decide to come back. Unlike most other nations, the United States does not have a passport control program for people leaving the country. Hence, when sketchy information on emigration was collected, it was deemed too unreliable to be of any analytical value. Accordingly, it is not possible to determine net immigration flow. There is no doubt, however, that immigration exceeds emigration in the 1980s by several multiples.

As for the behavioral link between the population and the labor force, it too has been difficult to anticipate. Actual labor force participation rates of subgroups of the population vary at given points in time and are sensitive over time to changing unemployment rates, inflation rates, fertility rates, family practices, and social attitudes. Thus, the wise aphorism-attributed to the physicist Niels Bohr-that "it is hard to predict, especially the future" applies to the art of forecasting actual labor force size or behavior.

\section{Labor Force Definition}

As with all economic measures, the civilian labor force has a particular statistical definition. The civilian labor force is composed of all persons in the noninstitutionalized population over 16 years of age who have a job plus those who meet a specific definition as being unemployed. The unemployed are those persons in the noninstitutionalized population who are 16 years of age or older who do not work and who are willing, able, available, and "actively seeking" work.

The civilian labor force, however, does not include those persons who want to work but who, because of the state of the economy, have abandoned active search for a job because they believe such efforts would be fruitless. Such potential labor force participants are called "discouraged workers." Research has shown that the more people who are unemployed at any given time, the more who tend to be discouraged (and vice versa). It also reveals that women in general as well as younger and older men are most likely to be affected by this phenomenon.

With the high aggregate unemployment levels of the mid-1980s, the number of discouraged workers has held at the high level of about 1.2 million persons over the past 3 years. Because they are not actively seeking a job, discouraged workers are not officially counted as being unemployed and, therefore, are excluded from being counted in the civilian labor force.

On the other hand, the definition of the civilian labor force does include as being employed all persons who desire to work full time but who can only find part-time jobs because of prevailing economic conditions. In the first quarter of 1987, the involuntarily part-time employed work force totaled 5.4 million workers.

Thus, the official definition of the civilian labor force has limitations. Therefore, the definition of who should be included and who should not is, periodically, a heated subject of both political and professional controversy (3).

\section{The Unique Experience of the United States}

Since the mid-1970s, the civilian labor force of the United States has been growing at a sustained pace of about 2.2 million net additional job seekers a year (from 93 million in 1975 to 117.8 million in 1986). In terms of those acu , lly able to find employment, their numbers also have increased significantly from 85.8 million to 109.5 million over this same time span. This growth in absolute numbers is not found in comparisons with any of the other major industrial powers of the free world (Table 1). Only Canada and Japan have shown any appreciable absolute increases in the size of their respective labor forces over this period. In West Germany and Great Britain the number of employed persons was actually smaller in 1985 than it was in 1975 (that is, they have sustained negative growth in employment and soaring unemployment). For France, Italy, and the Netherlands, employment changes have been

Table 1. Civilian labor force, employment, and unemployment for ten countries, in 1975 and 1985. Data for Canada, Australia, Japan, and the European countries have been adjusted to approximate U.S. labor force definitions. Numbers in thousands; unemployment rates in percentages (11).

\begin{tabular}{|c|c|c|c|c|c|c|c|c|c|c|}
\hline $\begin{array}{c}\text { Employment } \\
\text { status and } \\
\text { year }\end{array}$ & $\begin{array}{l}\text { United } \\
\text { States }\end{array}$ & Canada & Australia & Japan & France & $\begin{array}{c}\text { West } \\
\text { Germany }\end{array}$ & $\begin{array}{l}\text { Great } \\
\text { Britain }\end{array}$ & Italy & $\begin{array}{l}\text { Nether- } \\
\text { lands }\end{array}$ & Sweden \\
\hline \multicolumn{11}{|l|}{ Labor force } \\
\hline 1975 & 93,775 & 9,974 & 6,169 & 52,530 & 21,600 & 26,130 & 25,130 & 20,080 & 4,820 & 4,123 \\
\hline 1985 & 115,461 & 12,639 & 7,272 & 58,820 & 23,330 & 27,090 & 26,960 & 21,800 & 5,690 & 4,418 \\
\hline \multicolumn{11}{|l|}{ Employment } \\
\hline 1975 & 85,846 & 9,284 & 5,866 & 51,530 & 20,700 & 25,230 & 24,000 & 19,480 & 4,570 & 4,056 \\
\hline 1985 & 107,150 & 11,311 & 6,670 & 57,260 & 20,910 & 24,960 & 23,420 & 20,490 & 4,890 & 4,293 \\
\hline \multicolumn{11}{|l|}{ Unemployment } \\
\hline 1975 & 7,929 & 690 & 302 & 1,000 & 900 & 890 & 1,130 & 610 & 250 & 67 \\
\hline 1985 & 8,312 & 1,328 & 602 & 1,560 & 2,420 & 2,130 & 3,540 & 1,310 & 800 & 125 \\
\hline \multicolumn{11}{|l|}{$\begin{array}{l}\text { Unemployment } \\
\text { rate }\end{array}$} \\
\hline 1975 & 8.5 & 6.9 & 4.9 & 1.9 & 4.2 & 3.4 & 4.5 & 3.0 & 5.2 & 1.6 \\
\hline 1985 & 7.2 & 10.5 & 8.3 & 2.6 & 10.4 & 7.9 & 13.1 & 6.0 & 14.1 & 2.8 \\
\hline
\end{tabular}




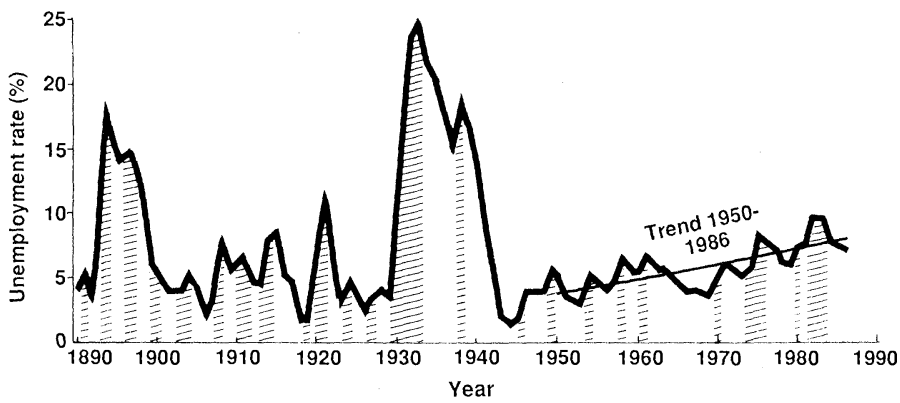

Fig. 1. Annual unemployment rates for the United States from 1890 to 1986. Shaded areas represent periods of economic recessions; unshaded areas represent periods of general economic prosperity (12).

barely positive, and the ranks of the unemployed have swelled. Canada and Australia have been able to provide more jobs but not at a sufficient pace to keep their unemployment rates from significantly increasing. Even Japan and Sweden have sustained increases in unemployment, but their rates still remain below what would be considered full employment in other countries.

Although the U.S. economy has generated an enormous number of jobs since 1975, it has not been able to create sufficient employment opportunities to keep the unemployment rate from drifting upward during periods of general prosperity (Fig. 1). Before World War II, the U.S. economy was subject to roller coaster-like swings in its unemployment experience. But with the advent and application of macroeconomic policies (that is, fiscal and monetary policies) since World War II, the wild gyrations in the U.S. economy have been modulated. On the other hand, the gradual upward creep in the unemployment rate since 1950 (shown by the trend line in Fig. 1) indicates that the U.S. economy is confronted with increasing labor force adjustment difficulties. Because the labor force is not homogeneous, the composition of its growth is crucial to understanding the challenges to adjustment and to formulating the human resource policies needed to ease adjustment.

\section{Explanations for U.S. Labor Force Growth}

Three major forces have contributed to the rapid growth of the U.S. labor force over the past decade. Each of these pressures has also exerted significant influences on the gender, age, and ethnic composition of the labor force. The forces are the unprecedented number of women who have sought entry into the labor market, the maturing of the post-World War II "baby boom" population cohort, and the acceleration in the number of immigrants coming to the United States. All of these factors are likely in varying degrees to continue to exert considerable influence into the 1990s.

Female workers. More women in both absolute and relative terms have been entering and staying longer in the labor force than at any previous time in the nation's history. The movement has been so abrupt and so large that it can be fairly described as being a "social revolution" in its own right. Two out of every three new labor market entrants since 1975 have been women, and the same pattern is forecast to continue through 1995 . The labor force participation rate of all women has risen sharply from $33.9 \%$ in 1950 to $54.4 \%$ in 1986. In total, women constituted about $45 \%$ of the civilian labor force in 1986, and it is projected that this percentage will increase to $47 \%$ by 1995 .

The contributing factors for this growth rest with the rapidly increasing participation rate of married women in general and married women with children in particular. It is the labor market behavior of the latter female workers that represents the dramatic departure from the past. Single adult women usually were in the labor market, but married women and women with children were not. The participation rate of married women has risen from 23.8 to $54.7 \%$ from 1950 to 1986 . The rate for women (married or not) with children under 18 years of age has grown from $45.9 \%$ in 1975 to $54.7 \%$ in 1986 . For women with children under 3 years of age it has increased from 34.1 to $50.8 \%$ over this same span. Under these circumstances of rapid change in social behavior, no one can predict what the normal labor force participation rate for women will be. It is projected, however, that the female labor force participation rate will continue to increase into the mid-1990s (4).

The reasons for the sudden acceleration of women in the labor market are still the subject of debate. The movement was completely unpredicted by demographers and labor market forecasters. The mechanization of housekeeping tasks since the end of World War II combined with the growing acceptance of family planning and the availability of new methods to permit the timing of birth occurrences created an opportunity for the social change to occur. The momentum to alter the status of women in the workplace was provided in the 1960s by the civil rights movement. Women were not initially included in the Civil Rights Act of 1964 but as the result of an amendment, prohibitions against sex discrimination in employment were included in the final legislation. The moral force of the law, combined with the creation of a legal enforcement mechanism, provided the emerging feminist movement with a lever to attack barriers that had previously prevented women from fully participating in the labor market. The momentum for change was subsequently prodded by the prolonged period of inflation that occurred during the 1970s and early 1980s. The decrease in real family incomes forced many women to find jobs in order to maintain their family's previous standards of living. In the wake of these occurrences, there has also been a surge in the number of female heads of households. In 1985, 16.2\% of all families were so constituted-up from $10.8 \%$ in 1970 . For black families, the percentages increased from $28.3 \%$ in 1970 to $43.7 \%$ in 1985 . Aside from single adult women, widowhood, divorce, and pregnancies outside of marriage have caused an increasing number of other women to be the sole breadwinners for their families; many such women have been forced to seek employment whether they wished to or not.

An important population corollary to the growth of female participation in the labor market is the decline in family size. The number of children per family in the United States has fallen from 3.2 in 1930 to about 1.8 in the mid-1980s. A sustained rate of 2.1 children per family is needed for population replacement. The most significant encouragement to smaller families has been provided by the advance of married women into the labor force. In the future, it is highly unlikely that women will abandon the financial and personal independence that they have come to experience. This is especially the case since divorce has become so common (about half of all marriages will end in divorce given current averages). Thus, high labor force participation by women is likely to be a permanent feature of the U.S. economy as will be the pattern of smaller families.

One consequence of these family trends has been that the number of new labor force entrants who are native born has been declining in the 1980s and will continue to do so until the mid-1990s. But, as opposed to other industrialized nations where similar declines in family size have occurred, the growth in the labor force of the United States is likely to be only marginally influenced, if at all. Immigration of foreign-born persons will probably serve as a substantial offset. Moreover, the "baby boom" generation is having an echo effect. Because of their large numbers, the members of this age group are producing a large number of children even though individual family sizes are shrinking. Between 1980 and 1986, the 
number of children under age 5 increased by $10.9 \%$ (to $18,128,000$ children in 1986). It is the only age cohort under 24 years of age to show a positive rate of increase over this period. Hence, by the late 1990s the predicted decline in native-born labor force entrants should be reversed.

The maturing of the population. The rapid growth of the labor force has also been significantly affected by the age distribution of the U.S. population. It currently contains a large "bulge" in the age range between 25 and 44 years of age. Not only is it the largest cohort of the population, but it is also the most rapidly growing. The bulge is a direct result of the labor force entry of the postWorld War II baby boomers (those born between 1946 and 1964) who have now matured into prime working-age adults. Of the nation's population in 1986 of $241,596,000$ people, a total of $76,127,000$ were in this age cohort (or $31.5 \%$ of the total population). If this cohort is broken into its two component parts, the age 25 to 34 grouping totals $42,984,000$ persons (it grew by $15.4 \%$ between 1980 and 1986), while the age 35 to 44 grouping contains $33,143,000$ people (it grew by $29.0 \%$ between 1980 and 1986). Regardless of gender or race, persons in the 25 to 44 years of age cohort of the population have the highest labor force participation rates of the entire labor force. If ever a person is going to seek work, it is most probable he or she will do so between these ages. Fortune magazine has dubbed this population distribution of the 1980s as being "demography's glad tidings" for the economy because it affords the U.S. economy the potential for a significant productivity bonus (5). Thus, the bulge is a "good" problem to be confronted with-especially when its implications are compared to the earlier time when this age group was in its youth (before 1980) or what lies ahead when this cohort enters its retirement phase (after 2001).

In this regard, one should note that the racial and ethnic composition of the "baby boom" population is also affecting the composition of the labor force. Although family size is decreasing for all major racial and ethnic groups, the decline began earlier and has been more rapid for non-Hispanic whites than for blacks and Hispanics. As a consequence, the proportion of the labor force that is black has risen from $9.9 \%$ in 1975 to $10.7 \%$ in 1985 , and the proportion that is Hispanic has grown from $5.3 \%$ in 1980 to $6.7 \%$ in 1985. The labor force growth rate of both groups has been increasing annually since 1980 at a faster rate than that of the overall labor force (6). Together, blacks and Hispanics accounted for $40 \%$ of the absolute growth in the labor force between 1980 and 1985 Data for other minority groups, such as Asians, are not collected on a monthly and annual basis, but their numbers are also growing rapidly. Thus, minority workers are becoming a larger proportion of the labor force each year, and they will continue to do so for the remainder of this century.

The new wave of immigrants. The last factor contributing to the rapid growth of the U.S. labor force is a phenomenon unique to the experience of the U.S. economy. It is immigration. Since the mid1960s, immigration has slowly reemerged as a key characteristic of the U.S. population and labor force (7). In contrast to all other advanced industrial nations, the United States stands virtually alone in its willingness to admit each year hundreds of thousands of legal immigrants and refugees for permanent settlement as well as to tolerate mass abuse of its laws by an even larger annual number of illegal immigrants. Indeed, a 1986 study of contemporary American society commissioned by three large U.S. corporations and conducted by an international team of scholars proclaimed that "America's biggest import is people" $(8$, p. 20$)$. Its detailed analysis, which generally documents "the decline in American exceptionalism," stated that the one feature to distinguish the current U.S. economy from those of other industrialized nations is that "immigration continues to flow at a rate unknown elsewhere in the world" $(8, \mathrm{p}$.
20). This observation, as significant as it is, was made before the passage of the immigration reform act of 1986 whose liberal amnesty provisions will guarantee that immigration levels for at least the next decade will soar to heights never before imagined. Moreover, it remains to be demonstrated whether the new law will have any real effect on reducing the flow of illegal immigration-the primary rationale for its enactment. The absence of an effective identification system, concern over inadequate funding for enforcement, and the omission of any attention to the powerful "push" forces of population growth, poverty, unemployment, and corruption in the countries of origin of the illegal immigrants all suggest that illegal immigration will continue at high and, possibly, increasing levels.

As for the other industrialized nations, Japan accepts no immigrants and few refugees. In Western Europe, the major industrialized countries pursued temporary foreign worker policies in lieu of seeking permanent immigrants to meet labor shortages in the postWorld War II era. Since 1973, however, even these "guestworker" policies have largely been abandoned, and little, if any, encouragement is now given for new immigrants. Most of these nations have also taken much stronger steps in the 1980s than the United States to discourage illegal immigration and to reduce refugee admissions. With stagnant or declining labor forces, they have elected to restrict entry and focus policy attention on the qualitative aspects of human resource development for their citizens.

The 1980 census revealed that the size of the foreign-born population of the United States had not only reversed its 50-year downward decline but had sustained a quantum increase. As a group, the reported foreign-born population rose from 9.6 million in 1970 to 13.9 million persons in 1980 (an increase of $45 \%$ ). No other grouping of the personal characteristics of the population increased by a larger percentage than that of the foreign born between 1970 and 1980. The 1980 census also disclosed that one of every ten people in the country spoke a language other than English at home. As it is certain there was a substantial statistical undercount of the illegal immigrant population by the 1980 census, even these official findings were surely understated. Given the momentous immigration developments since 1980 , the foreign-born population to be recorded by the 1990 census will show another quantum leap. For this reason, the demographer Leon Bouvier has observed that "immigration now appears to be almost as important as fertility insofar as U.S. population growth is concerned" (9, p. 1). Since population changes are transmitted to the nation's economy through labor force changes, Bouvier warned that "there is a compelling argument for close coordination between the formulation of employment and immigration policy" $(9$, p. 23$)$. So far, his pleas have gone unheeded.

Immigration is also contributing to dramatic changes in the racial and ethnic composition of the U.S. population and labor force. About $85 \%$ of the legal immigrants and refugees admitted to the United States since the mid-1970s have come from either Latin America or Asia. Over this period, the six countries of origin that account for the largest numbers of the new legal immigrants and refugees are Mexico, Vietnam, the Philippines, Korea, ChinaTaiwan, and Cuba. The last time a European country appeared as a major source of new immigrants was in 1973 when Italy ranked fifth. Moreover, it is undebatable that most illegal immigrants to the United States over this same time span have also come from Latin America and Asia. Many illegal immigrants from these countries will be the beneficiaries of the new amnesty programs. Thus, both the population and the labor force of the United States are becoming more pluralistic in their ethnic and racial composition than ever before.

Immigration is the one aspect of labor force growth that public 
policy should be able to control, but to date it has not been willing to do so. The design of immigration policy, in all of its forms, is still dominated by the pursuit of purely political objectives, and it has yet to be held accountable for its sizable economic consequences. Less than $5 \%$ of the immigrants and refugees who are legally admitted to the United States each year are admitted on the basis that the skills and education they possess are actually in demand by U.S. employers. The percentage is considerably less than $1 \%$ if illegal immigrants are included in the total immigrant flow.

The overall picture. As a result of the aforementioned developments, the overall labor force participation for the U.S. population reached an all-time high of $65.3 \%$ in 1986 . The comparable rate for 1950 was $59.7 \%$; for $1960,60.0 \%$; for $1970,61.0 \%$; and for 1980 , $64.1 \%$.

Never in the country's history have so many persons-in both percentage and absolute terms-sought to work. It is likely that both figures will continue to rise for the above-discussed reasons in the decade ahead. As a consequence, the economy of the United States will continue to be under relentless pressure to create sufficient job opportunities for the burgeoning number of job seekers.

\section{The Worrisome Exception}

There is, however, one disturbing countertrend buried in the euphoria over the rising labor force participation rate of the overall U.S. population. It has been the persistently lower labor force participation rate of black males relative to white males. Historically through the 1940s, the black male labor force participation rate consistently exceeded that of white males. But since the 1950s, the white male rate has passed the black rate and the gap between the two has widened considerably. By 1986, the white male rate exceeded the black male rate by 5.7 percentage points (76.9 to $71.2 \%)$. The wide gap exists for every age grouping. Indicative of the significance of this decline in black male participation is the fact that the absolute number of black men in the labor force just barely exceeds that of black women (6.3 million black males to 6.2 million black females in the labor force in 1986).

On the surface, there seems to be no reason why white males should have a significantly higher participation rate for every age cohort than black males or that white males should have a considerably higher overall rate. However, blacks are clustered disproportionately in the inner cities of 12 major cities and are scattered throughout the large geographic area of the rural South. Jobs in these locations are frequently scarce. But jobs are especially hard to find if one has few skills and little education and if there are limited opportunities to acquire skills or to develop latent abilities. Qualifying for the jobs is made more difficult if there are lingering practices of racial discrimination. It is also likely that the new wave of immigrants, especially illegal immigrants, who have also disproportionately settled in inner city areas, has increased the competition for jobs at the entry level. Under these conditions, an inordinate number of black males apparently have despaired from seeking work in the regular economy.

There is, of course, an ominous societal implication to these low black male participation rates. If adult black males are not at work, or in school, or in the military, what are they doing to survive? It seems that an urban subclass of adult black males who function outside the normal labor market has formed and institutionalized its existence through irregular activities such as crime, alcoholism, and drug addiction. Helping those black male adults who can be reattracted into the regular labor market and preventing many black male youths from succumbing to a similar fate are major policy challenges of contemporary times.

\section{Final Thoughts}

The continuing growth of the civilian labor force has placed the U.S. economy under severe strain to provide a sufficient number of jobs for those who seek them. Moreover, matching job seekers with available jobs is not automatic. The rapidly changing composition of the civilian labor force has complicated the matching process. It is anticipated that $80 \%$ of the labor force entrants for the remainder of this century will be composed of women, minorities, and immigrants $(10)$. For historical and institutional reasons, members of these groups have usually had difficulty securing the necessary job preparation and receiving fair opportunities to compete for the available jobs. Hence, these changes in the size and composition of the labor force dictate that qualitative human resource policiessuch as education, training, retraining, labor information, and labor mobility programs-become integral components of national economic policy. The traditional reliance on fiscal and monetary policies that focus only on the demand for labor are unlikely to ensure satisfactory labor force adjustment. Human resource policies specifically designed to enhance the job qualifications of the emerging supply of labor will be more necessary than ever before. If such policy endeavors are undertaken on an enlarged scale from what currently exists and if they are combined with rigid enforcement of the nation's equal employment opportunity and immigration laws, the prospects for full employment, general prosperity, and domestic tranquility are good. If such steps are not taken and if human resource policies are not given high and immediate priority, the logical consequences are reason for concern and, possibly, alarm.

\section{REFERENCES AND NOTES}

1. F. H. Harbison, Human Resources as the Wealth of Nations (Oxford Univ. Press, New York, 1973); T. W. Schultz, Am. Econ. Rev. 51, l (March 1961); E. F. Denison, Trends in American Economic Growth, 1929-1982 (Brookings Institution, Washington, DC, 1985)

2. V. M. Briggs, Jr., Int. Migr. Rev. 18, 623 (fall 1984).

3. Definitional details and a review of the related policy issues appear in a report by the National Commission on Employment and Unemployment Statistics [Counting the Labor Force (Government Printing Office, Washington, DC, 1979)]

4. H. N. Fullerton, Jr., Mon. Labor Rev. 108, 17 (November 1985).

5. W. Guzzardi, Jr., Fortune 100, 92 (5 November 1979).

6. R. E. Kutscher, in Job Generation: U.S. and European Perspectives, H. Rosen, Ed. (Olympus, Salt Lake City, UT, 1986), pp. 10-14

7. V. M. Briggs, Jr., Immigration Policy and the American Labor Force (Johns Hopkins Univ. Press, Baltimore, 1984)

8. Oxford Analytica, America in Perspective (Houghton Mifflin, Boston, 1986)

9. L. F. Bouvier, The Impact of Immigration on the Size of the U.S. Population (Population Reference Bureau, Washington, DC, 1981).

10. W. E. Brock, speech before the National Press Club, Washington, DC, 5 March 1987, p. 10 (mimeographed material).

11. U.S. Department of Labor, Mon. Labor Rev. 109, 89 (December 1986)

12. Data are from the U.S. Department of Labor, Washington, DC. 